\title{
Qualimetric assessment of management in the field of development
}

\author{
Olga Chumakova ${ }^{1, *}$ \\ ${ }^{1}$ Moscow State University of Civil Engineering, Yaroslavskoe shosse, 26, Moscow, 129337, Russia
}

\begin{abstract}
Sustainable economic growth and progressive development of the Russian economy are necessary to improve the well-being of the population of the Russian Federation and to fully meet human needs. These goals can be achieved by solving various economic problems, including the problem of the best use of material and human resources available to a single economic entity, the region and the economy as a whole, which is one of the main problems of economic science. In this regard, the relevance of the study of the intensification of investment and construction activities (ICA), which allows improving the use of economic resources, is always high. It is especially important in the context of economic crises, when the fall in consumer demand, economic growth slows down, the volume of production of enterprises and the sale of goods, works and services, regional product and gross domestic product are reduced, and therefore, to minimize losses, the subjects of economic activity are increasingly paying attention to reducing the cost of used resources and increasing the efficiency of their use. The scientific novelty of the research consists in the development of methodological foundations of intensification on the basis of an integrated approach implemented by methods of determining the feasibility of intensification of investment and construction activities and the efficiency of the investment and construction complex.
\end{abstract}

\section{Introduction}

The direction of development of the modern economy is largely determined by the key economic postulate on the choice of the method of use of limited resources. Under these conditions, the achievement of a better, more effective result of the use of available resources is possible with the intensification of all economic activities.

At the modern construction enterprise of the regional level, which is a complex structured system consisting of two main interconnected subsystems - control and managed, within the framework of the managed subsystem of the construction enterprise, the resources necessary for the construction are accumulated, the technological processes of construction work are carried out, the finished products, works and services are sold. The basis of the management subsystem is the selection and implementation of management

\footnotetext{
*Corresponding author: 7406976@gmail.com
} 
actions on the managed subsystem, which include: planning, organization, control and analysis of activities, motivation of employees [1].

Some authors define the structure of the management subsystem in the management system of the organization through the following components - strategic marketing, tactical marketing, production organization, rational management decisions, personnel management, innovation management, operational management of implementation of decisions and financial management [2].

To improve the activity of the investment and construction complex, to increase its effectiveness, it is important to determine and evaluate the relationship between the intensification and efficiency of the activities of both the managed and the managing subsystems of the enterprise [3].

Methods of evaluation of the intensification of the controlled subsystem are now widely represented in the works of domestic and foreign economists. The indicators of the intensification assessment are based on the calculations of the economy of the total social labor, both living and materialized. Such indicators include the savings of labor costs, materials, and other resources on the issue of a unit of production, increasing productivity, increasing material returns, return on assets, and return on invested capital [4].

The evaluation of the intensification of the control subsystem activity in comparison with the evaluation of the managed subsystem of the construction enterprise is studied to a lesser extent [5].

In addition to the resources used for the operation of the managed subsystem of the enterprise - material (production, financial, commodity) and human labor resources, the management system uses the knowledge of the individual production processes and the ability to organize these processes, that is, information and organizational and entrepreneurial human resources [6].

These resources, by their fundamental nature, are labor resources. That is, as well as in production processes, in the management processes of the production subsystem requires a certain number of people and their time to carry out activities [7]. The difference between the use of entrepreneurial resources and labor is the absence of a proportional relationship between the number of live labor in the usual sense and the number of products, works and services. In other words, indicators of labor productivity-development and labor intensity do not provide an objective assessment of labor of employees of the management subsystem in terms of their use of information and organizational and entrepreneurial resources.

\section{Methods}

The methodological basis of the study was the method of abstract review, historical and structural-logical methods, methods of deterministic, regression and economicmathematical analysis, as well as complex and systematic approaches to the intensification of investment and construction activities. The research process was carried out using General scientific methods of scientific observation, description, classification, idealization, formalization, axiomatization, hypothetical-deductive method and the method of mental experiment, information, system and complex approaches.

The information base of the research is empirical data describing the experience of Russian enterprises and organizations involved in investment and construction processes, innovation and contained in monographs, scientific articles and research, periodicals, materials of scientific conferences, Internet resources. The work also used data from the materials of the Federal state statistics service of the Russian Federation and its regional offices, other information agencies involved in the processing of statistical data of investment and construction enterprises, evaluating and systematizing innovation processes. 


\section{Results}

One of the important aspects of correlation of efficiency and intensification of activity is the assessment of efficiency of the intensification based on management of innovative activity of the enterprises. As noted in [8] the measurement of the effectiveness of innovations, as well as its evaluation and analysis, is one of the most difficult problems to solve which the authors propose the following methods:

- comparison of actual and standard costs and results before and after innovation;

- index method;

- evaluation of innovation and investment projects;

- risk management;

- assessment of the strategic vision;

- accounting for competitiveness.

In [9] there are four points of view on the question of the ratio of intensification and efficiency. It considers intensification as:

- the process underlying efficiency improvement;

- a phenomenon based on improved efficiency;

- causes and factors of production efficiency;

- the phenomenon, the economic content of which is reduced (as well as efficiency) to save time.

Categories efficiency and intensification are based on the relationship between the results and costs of production and economic activities. Due to intensification, greater efficiency is achieved and it plays the role of a factor, a cause, and efficiency - the role of the consequence, the result, that is, there is a causal relationship between these categories.

The use in economic activity mainly intensive way of development is aimed at improving the efficiency of social reproduction. The correlation between the categories of intensification and efficiency is that the first category characterizes the purposeful process of economic growth on the basis of improving the objects there, means of production, technological and managerial processes, organizational structures and forms. The second category (effectiveness) is a consequence of this process

The correlation between intensification and efficiency is that through improving the efficiency of the impact of production and economic processes through their intensification, which acts as an amplifier of the use of growth factors and effective ways of managing.

In the process of intensification, the totality of all costs and benefits must be considered in unbreakable unity. They are two sides of intensification, both in theory and in practice, and their consideration in isolation from each other can lead to a distorted understanding of the intensification processes. Different combinations of different types of costs, their elements and results are possible. For example, with the saving of live labor, it is usually necessary to increase the cost of means of production (for materialized labor), and the saving of objects of labor is associated with additional costs of labor and (or) means of production, while increasing labor productivity with constant intensification efforts after reaching the maximum begins to decline in accordance with the principles of optimality and finiteness of temporary methods of intensification formulated in paragraph 1.2 of the study. Thus, not any increase in the amount of resources used characterizes the growth of economic activity as extensive. But on the other hand can be effective not only rapidly growing production, as the improvement of the effect is possible in the case of extensive reproduction. That is, intensification is not the only reason for efficiency, but efficiency is not the only consequence of intensification [10]. 
For example, if the efficiency is increased only on the basis of the production field by concentrating it on the outdated technical and technological base, such an increase is not an indicator of intensification processes, unlike the case when the efficiency increase is due to the increase in the qualification of personnel and (or) the introduction of a new technical and technological base and the change in efficiency will be a manifestation of intensification measures.

Developing on a modern scientific, technical, economic and social basis, intensive reproduction not only improves the use of existing production relations and productive forces, but also allows you to qualitatively improve them both on the basis of scientific and technological progress, and through investment in qualitatively new, more efficient means and objects of labor and in improving the professional qualification level of personnel

Thus, the assumption made in section 1.1 of the study that both types of economic growth - intensive and extensive - are not pure in practice is further confirmed in terms of the correlation between the categories of efficiency and intensity. It can be argued that in practice these types of reproduction are closely intertwined with each other. It can be argued that, on the one hand, intensification is accompanied, including the development of production and economic activities at the achieved technical and technological level, and on the other hand, and with the most developed industrial relations and productive forces, with the dominance of an intensive type of reproduction, there may be an extensive type of growth. For example, in any industry, even with the most modern means and objects of labor with the growing need for products, works or services can be an increase in the number of personnel.

From the point of view of growth of productivity of live work now it is accepted to distinguish the Fund-saving and Fund-intensive forms of intensification. Fund-saving intensification is based on reducing the cost of both live labor and materialized, and Fundintensive on the growth of productivity of live labor by increasing the number of costs of materialized labor. At the same time, in the case of a Fund-saving form of intensification, it is possible to outpace the reduction in the cost of past labor in comparison with the cost of living. Thus, the common definition of productivity growth through the reduction of living labor spent on production or performance of work with the growth of materialized labor takes into account only one form of intensification - Fund-intensive, and Fund-saving intensification remains outside the scope of research.

The efficiency of intensification is determined by comparing the results of production and economic activities and costs. At the same time, it is necessary to distinguish between the efficiency of intensification and intensification as a process from its previously achieved level. If we consider the level of intensity, for example, through a comparison with the normative values or based on the benchmarking method, that is, with the results of enterprises - leaders of the industry, it will reflect the current state of the main elements of production and economic activity, the speed of implementation of technical and technological and organizational management processes, the degree of saturation of innovative means and objects of labor, etc. and the efficiency of intensification reflects the level of use of these resources.

Since the same means of production can be used differently, the efficiency of intensification depends on their combination. The choice of the optimal set of tools used in production and economic activities, while respecting their compliance with each other, allows achieving maximum efficiency. At the same time, being one of the decisive factors of increase of production efficiency, the intensification way of development serves as the direction of increase of productivity of public work.

Based on the above, we can say about the direction of intensification to increase the number of the final result in the selected socio-economic system through the optimal use of resources through the introduction of scientific and technological progress, rationalization 
of organizational and managerial structure of production, the use of innovative methods of motivation and enterprise management.

Thus, the efficiency of production and economic activities, as a consequence of its intensification, is caused by the excess of the growth rate of the growth of the results of activities caused by the intensification over the growth rate of the costs that caused them.

However, being the basis of investment and construction efficiency, intensification does not serve as its analogue, since efficiency is the result of both intensive and extensive forms of its development. The essence of intensification through increasing the impact of materialized and live labor, through the acceleration of technical and technological, organizational and managerial processes on the basis, including the inclusion of previously untapped reserves and creative, innovative potential.

For intensification is characterized by the fact that the progress of production relations and productive forces allows an increasing amount of funds and objects of labor and the entire mass of production and economic activity to carry out with the help of a decreasing amount of human resources. At the same time, the increasing mass is understood not as a simple set of advanced technologies and effective means and objects of labor, but their integration, on the basis of organic synthesis due to scientific and technological progress, transforming and improving technologies and techniques of production activities, changing methods and methods and forms of organization of labor and production.

\section{Discussion}

To solve the problem of finding ways of the best use of resources in investment and construction activities on the basis of its intensification, the study analyzes approaches to the essential content of the concept of "Investment and construction activities". To this end, the concept of investment and construction activities in terms of determining its properties through the growth of entropy and the objectivity of the positive synergetic effect due to the fact that investments that create new capital, clearly increase the strength of counteraction to the external environment of the socio-economic system in which they are involved.

The subject of the research is the management relations of participants of investment and construction processes in the innovation-oriented economy, arising in the process of making decisions on the choice of forms and methods of implementation of capital reproduction processes.

The first Chapter of the work analyzes the state of the investment and construction complex from the standpoint of the degree of optimality, the intensity of the processes occurring in it. For this purpose, a method of assessing the degree of optimality of investment and construction processes at the regional level based on determining the elasticity of the effect in relation to the attracted resources in the investment and construction complex of the region is proposed. It was tested on the basis of statistical data on the state of the investment and construction complex of the city of Moscow.

The degree of intensification of reproduction processes with attraction of investments in the investment and construction complex of the city of Moscow by subjective (expert survey) and objective methods with the use of the classification of methods of intensification of investment and construction activity developed within the framework of the dissertation work, which formalizes and links the methods, methods and basic principles of intensification and is based on the division of methods by type of resources used.

In the period from 2009 to 2016, the investment and construction complex in St. Petersburg is developing along a non-optimal path; the development has a trend to reduce the optimality and goes mainly in an extensive way, i.e. by increasing the number of resources involved in investment and construction activities. 
In order to find ways to improve the use of resources and the transition from extensive to intensive path of development, the paper assesses the role of innovation in the processes of intensification of investment and construction activities: the Concept of marketing innovation, combining two approaches to their creation and dissemination.

Based on the results of the work done, the object of the study - the essential forms of capital reproduction processes in terms of their intensity, i.e. exceeding the resulting complex effect growth over the increase in resource costs, is clarified. Their basis innovative development-is defined. The basic principles of which are formulated and classified: empirical principles developed through the practical implementation of innovation activities, methodological principles that combine the basic system techniques and methods characteristic of effective innovation and worldview, those that in modern conditions make it possible to adapt the results of innovative development to everyday human activities, and Vice versa.

Investment and construction complex and investment and construction activities at each of the economic levels: the macro - level of the economy as a whole, the meso - level of a separate region, the micro - level of a separate enterprise, are a system consisting of two subsystems-managing and managed. To intensify each of the subsystems, different methods and techniques are used. To intensify the activities of the controlled subsystem, a model of intensification of investment and construction activities on the basis of space-time optimization of technological processes has been developed.

To intensify the activities of the management subsystem collected, classified and refined methodical apparatus of its intensification on the basis of rationalization of the management structure of the enterprise.

The success of the intensification of investment and construction activities is determined on the basis of evaluating the effectiveness of the proposed measures, methods and algorithms. The qualitative component of the concept of "efficiency" as a characteristic of investment and construction activity is revealed through the quantitative characteristic of the type of economic development-extensive or intensive. To assess the level of intensification of the management system, a technique based on the introduction of the concept of "the Rate of reproduction of fixed assets of the enterprise" - the ratio of the level of reproducible capital in the enterprise with the level of reproduction of capital in the enterprise leader of the industry for the period under review.

\section{Conclusion}

In conclusion, in order to clarify the results of the study from the standpoint of compliance, the mechanisms of the complex not to reduce the efficiency of the processes occurring in the investment and construction activities of the region, the methodology for assessing the level of innovation activity is clarified, based on the concept of "Norm of consumer properties of finished construction products" at the regional level and on its basis and on the basis of the method of assessing the level of intensification of the control system is supplemented by appropriate restrictions economic and mathematical model of intensification of the controlled subsystem on the basis of space-time optimization of technological processes.

In the course of the work done in the study, the methodical apparatus providing an opportunity for theorists and practitioners of investment and construction activities on the basis of its intensification with the help of innovation-oriented development of investment and construction complex to improve the use of material and human resources involved in it, to increase the efficiency of investment and construction economic. 


\section{References}

1. L. Becker, Business development management: der operative arm der strategischen führung, 1, 9-25 (2018) https://doi.org/10.1007/978-3-658-20089-3_3

2. S. Kafandaris, Journal of the Operational Research Society 44(11), 1163-64 (1993) https://doi.org/10.1057/jors.1993.190

3. Script Development Management, Shell Scripting Recipes: A Problem-Solution Approach, Apress, 397-405 (2005) https://doi.org/10.1007/978-1-4302-0024-6_20

4. L.A. Colaianni, Proceedings of the 5th European Conference of Medical and Health Libraries, Springer Netherlands, 13-17 (1997) https://doi.org/10.1007/978-94-0158786-0_3

5. G. Edington, Property Management: A Customer Focused Approach, Macmillan Education, 127-135 (1997) https://doi.org/10.1007/978-1-349-14258-3_9

6. Y.X. Zhang, X.Sh. Men, H. Wang, G.J. Zhi, Proceedings of the International Conference on Information Engineering and Applications (IEA), Springer London 875-81 (2013)

7. P. Ricardo, The European Journal of Development Research 21(5), 813-14 (2009) https://doi.org/10.1057/ejdr.2009.42

8. C. García-Moreno, International Symposium on Distributed Computing and Artificial Intelligence, Heidelberg, Springer Berlin Heidelberg, 295-302 (2011)

9. B. Mukhamediyev, A. Khitakhunov, Country Experiences in Economic Development, Management and Entrepreneurship, Springer International Publishing, 63-87 (2017)

10. G.V. Haythorne, Strategy for Development, Palgrave Macmillan UK, 307-13 (1976) https://doi.org/10.1007/978-1-349-02896-2_17 